\title{
Geografia eleitoral: as articulações e relações das tramas territoriais, redes e fluxos no território fluminense
}

Electoral geography: the articulations and relations of the territorial plots, networks and flows in the "fluminense's" territory

Géographie électorale: articulations et relations des parcelles, réseaux et flux territoriaux du territoire "fluminense"

Geografía electoral: articulaciones y relaciones de tramas territoriales, redes y flujos en Río de Janeiro

\section{Bernardo Bispo Santos}

\section{(2) OpenEdition}

\section{Journals}

\section{Edição electrónica}

URL: http://journals.openedition.org/espacoeconomia/9780

DOI: $10.4000 /$ espacoeconomia.9780

ISSN: 2317-7837

\section{Editora}

Núcleo de Pesquisa Espaço \& Economia

Refêrencia eletrónica

Bernardo Bispo Santos, « Geografia eleitoral: as articulações e relações das tramas territoriais, redes e fluxos no território fluminense », Espaço e Economia [Online], 16 | 2019, posto online no dia 03 janeiro 2020, consultado o 10 janeiro 2020. URL : http://journals.openedition.org/espacoeconomia/9780 ; DOI : 10.4000/espacoeconomia.9780

Este documento foi criado de forma automática no dia 10 janeiro 2020.

(C) NUPEE 


\title{
Geografia eleitoral: as articulações e relações das tramas territoriais, redes e fluxos no território fluminense
}

\author{
Electoral geography: the articulations and relations of the territorial plots, \\ networks and flows in the "fluminense's" territory \\ Géographie électorale: articulations et relations des parcelles, réseaux et flux \\ territoriaux du territoire "fluminense" \\ Geografía electoral: articulaciones y relaciones de tramas territoriales, redes y \\ flujos en Río de Janeiro
}

Bernardo Bispo Santos

\section{Primeiras aproximações: o jogo de escalas político}

1 Neste artigo procuramos trazer aproximações que possam constatar as influências no meio político-eleitoral de famílias "consolidadas" no território. Pela articulação da esfera empírica, até as constatações factuais (dados estatísticos, conteúdos noticiados e depoimentos) ao escopo teórico classificatório para tamanhas tramas.

Para um maior entendimento da temática sendo apresentada aqui, é preciso ter consciência de um recorte que, de certa forma se apresenta confuso nas maiorias das ocasiões em trabalhos. Em um básico jogo de escalas, a região discutida neste artigo se é denominada de "Baixada Fluminense". Por ser tratar de uma região que recentemente é debatida (no meio científico), podemos destacar sua delimitação territorial, que se apresenta bastante variada de acordo com o autor e a datação de sua obra. Para este trabalho, utilizaremos a classificação de SIMÕES (2006), delimitando a Baixada Fluminense em polos: Nova Iguaçu e Duque de Caxias como centralidades constituídas ${ }^{1}$, incluindo também seus "satélites" que cercam tais centralidades, tais como: Belford 
Roxo, São João de Meriti, Nilópolis, Mesquita, Queimados, Japeri. A diferenciação da concepção original para o artigo aqui presente, é a adição dos municípios de Seropédica, Itaguaí como cidades que permeiam essa borda "metropolitana", se provando como "satélites do limite". Em outras ocasiões dependendo de autores, Magé e Guapimirim podem ser inseridos na lógica regional da Baixada. Neste artigo também consideramos a entrada desses dois municípios na classificação.

3 Neste jogo de escalas, apresentamos o recorte analítico do trabalho, que se limita a analisar os bairros que estão englobados dentro da $84^{\circ}$ Zona Eleitoral do Estado do Rio de Janeiro, mais precisamente no município de Nova Iguaçu. Pelo recorte principal deste trabalho ser uma zona eleitoral, tendo isto em vista, foi elaborado um mapa para uma melhor visualização (Figura 1).

Figura 1 - Mapa da $84^{\circ}$ Zona Eleitoral do Rio de janeiro

MAPA DA $84^{\circ}$ ZONA ELEITORAL DO RIO DE JANEIRO
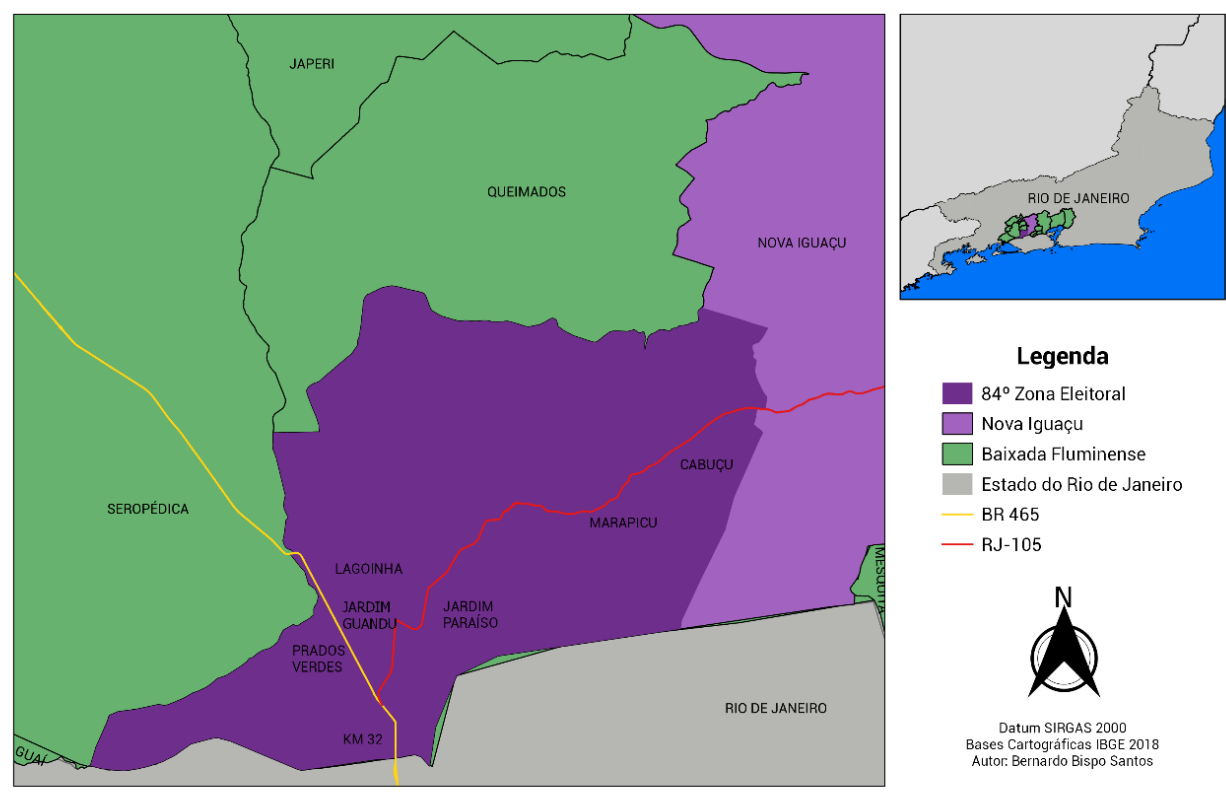

Legenda

$84^{\circ}$ Zona Eleitora

Nova Iguaçu

$\square$ Baixada Fluminense

Estado do Rio de Janeiro

BR 465

- RJ-105

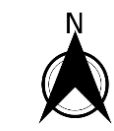

Datum SIRGAS 2000 Gases Cartográficas IBGE 2018

Figura - Mapa indicador do Recorte Espacial da Pesquisa. TER/RJ

Além da amostragem cartográfica, é importante ressaltar essa limitação analítica em bairros, que são compostos por: Km 32, Prados Verdes, Lagoinha, Jardim Paraíso, Jardim Guandu, Marapicu e Cabuçu. A consolidação de tal recorte é justificada quando pensamos em uma lógica que permeia a zona eleitoral, a mesma se efetiva tanto fisicamente, pelos eixos rodoviários como a BR-465 (Antiga Est. Rio-SP) e a RJ 105 (Est. de Madureira). Acreditamos que tal lógica segue por toda a zona eleitoral, por conta de uma espécie de "separação" territorial entre a região sudeste do município, além de outras regiões como a do Tinguá e bairros que cercam o centro de Nova Iguaçu. Essa sensibilidade é algo que, no território, se apresenta como uma realidade "comum", devido a tamanha "negligência" e "esquecimento".

Para definir o ponto de partida no aspecto temporal, devemos partir pela análise da conjuntura política que se configurava com uma "nova face", tendo em vista os períodos tenebrosos anteriores, a partir das eleições gerais de 1982. Este marco 
temporal se justifica pela mudança nas ambiências políticas da época, pois se vê aí uma espécie de "abertura" política. E a partir desses momentos, pode ser observado o "Efeito Brizola", esse fenômeno é dado essencialmente pelas políticas públicas de teor "populares".

6 Nos orientamos aqui em explicitar este acontecimento, pois a negligência da estrutura em um contexto de atuação "institucional" era gigantesca. A partir do governo Brizola (1983-1987), se vê uma maior "assistência" por parte institucional a região. O maior acesso à cidadania foi uma das maiores ações do governo perante a região, assim como questões primordiais como saúde e principalmente educação. Devemos também ter o cuidado de salientar que espécie de "assistência" é esta que foi dada a região como um todo. $O$ contexto do fim da década de 1970 para o início da década seguinte foi de uma movimentação na Baixada Fluminense pelo mercado imobiliário ${ }^{2}$, pelo inchaço da centralidade da metrópole carioca (SILVA, 2015). Podemos ter como exemplo, a questão da habitação, as grandes obras da Companhia Estadual de Habitação do Rio de Janeiro (CEAB). E ao nos dizermos em legado na contextualização desse "Efeito Brizola" (ALKMIN, 2014), embarcamos na efetivação dos Centros Integrados de Educação Pública, mais carinhosamente apelidados de "Brizolões". Ao nos relatamos ao que realmente se condiciona como foco principal, procuramos desvendar como tais famílias cresceram por via desta "abertura" política, para desaguar nas condições atuais da conjuntura política-eleitoral.

\section{Território, poder e eleição: a geografia eleitoral da $84^{\circ} \mathrm{z}$}

8 Para obtermos tamanha qualidade na análise do trabalho, utilizamos da Geografia Eleitoral, que se parte de uma ramificação da Geografia Política. A importância da Geografia Eleitoral no processo de formação deste trabalho é espacializar a questão eleitoral como um processo contínuo. Também é preciso acrescentar a importância de se usar a termologia "Geografia Eleitoral", e não "Geografia do voto". Apesar de parecerem semelhantes em suas formas de abordagens, o uso da nomenclatura "voto" diminui o fator de análise a se limitar somente a uma ação institucional. Em contrapartida, o processo eleitoral se dá a todo instante como uma ação política e nisto podemos dizer que o processo eleitoral não se limita somente a uma "campanhaeleição-pós eleição". Porém, o mesmo se expande, introduzido a uma espacialização, podemos utilizar uma metodologia que traz um maior apreço à ciência geográfica. Como "espaço-eleitor-eleição" (SANGUIN, 1981). A elevação do olhar geográfico é importante, pois, se há de problematizar o espaço constituído daquele tal lugar, a problemática e o maior destaque na questão espacial nos estudos eleitorais, se justifica quando pensarmos em poder. $\mathrm{O}$ tal poder se encontra atrelado à sua posição na conjuntura social. Entretanto essa conjuntura não é brutalmente capital em si, a consolidação daquele elemento como chave nessa "pirâmide social" só seria consolidada de acordo com a posição daquele elemento no território. Neste contexto é preciso afirmar que:

"Cada homem vale pelo lugar onde está: o seu valor como produtor, consumidor, cidadão, depende de sua localização no território. Por isso, a possibilidade de ser mais ou menos cidadão depende, em larga proporção, do ponto do território onde se está" (SANTOS, 1987). 
9 A relação dentre esses dois conceitos se justifica pelas constituições dos mesmos, tendo como pauta uma construção dessas "relações de poder". Tais tramas não são postas como uma espécie de "espaço natural", se é construído por uma historicidade local. Sobre tal relação de poder e território podemos afirmar:

“[...] ao mesmo tempo que o território corresponde a uma faceta do espaço social (ou, em outras palavras, a uma das formas de qualifica-lo), ele é, em si mesmo, intangível, assim como o próprio poder o é, por uma relação social (ou melhor, uma das dimensões das relações sociais). Se o poder é uma das dimensões das relações sociais, o território é a expressão espacial disso: uma relação social tornada espaço mesmo que não de modo diretamente material, como ocorre com o substrato, ainda que o território dependa, de várias maneiras, deste último. " (SOUZA, 2015, p. 97-98)

10 A "materialidade" descrita por Marcelo Lopes de Souza, pode ser considerada como expressões de poder, que possam ser: violência, persuasão, intimidação, dominação, pertencimento e eficiência. A discussão da efetivação dessa materialidade é importante, contudo, neste artigo também é de suma importância debater sobre a ação de um poder simbólico atrelado à territorialidade existente. O olhar geográfico traz uma elevação qualitativa a essa discussão, pois, temos que deixar claro que o fator espaço e território não pertencem a mesma cadeia naturalmente, apesar de andarem em conjunto, como pilares um para o outro (RAFFESTIN, 1993). Concluindo essa discussão, podemos destacar que as territorialidades existentes, não partem somente de uma ferramenta para a "criação" da ordem instituída, mas também se molda como um alienador das formas que regram a imagem de mundo que nos foi concebido (SACK, 1986). Essa alienação pode ser dada pela perpetuação de um certo território a um status préconcebido, podemos ter conceitos chaves que são automodelados a partir de tais concepções. A favela, comunidade e a periferia em tese, estão "condenados" a um ordenamento territorial, seja essa ordem partida pelo Estado, grupos paralelos de poder, etc. Reforçando a discussão anterior, a manutenção do poder se dá claramente pela manutenção do território em suas diversas maneiras. o congelamento do status quo em escalas variadas se dá como uma das maiores armas dessa "alienação" da forma do território. Voltando à HAESBAERT (2004), classificamos a territorialidade do artigo como uma "Territorialização político-funcionais", que podem ser definidas em uma mútua relação entre o instituído e o desinstituído. O território apresentado neste artigo, possui raízes profundas com seu passado recente, tendo vista a produção deste passado em relação com as centralidades cariocas, como fora citado anteriormente. A elevação da articulação entre poder e território se unifica na problemática do artigo, a partir do momento que se é possível observar ações que se delimitam e se regram de um modo a partir de determinado local.

11 Tendo em vista esse conjunto de fatores, propomos em enxergar essas complexas relações não se delimitando a enxergar somente o instituído governamentalmente, pois a região contém fatores particulares. Como o poder desconstituído, porém esse mesmo poder é a instituição em sua forma mais plena na região aqui discutida, em sua estrutura mais ampla de "institucionalidade". No cenário do conceito do significado de o que é poder, Estado e coercibilidade, tal região se diferencia por ter suas particularidades em diversas escalas, que precisam ser descritas e formuladas em um ato de ação instituída.

12 A Baixada Fluminense, que ainda possui sua representação moldada como a referência da precariedade, porém, este trabalho tem como proposito expor seus agentes condicionantes da formulação deste território, que são vastos e riquíssimos. Obtendo 
assim uma maior dificuldade em espelhar em outras regiões semelhantes, nos estudos do campo das ciências humanas. Seja pelos fatores condicionantes dos mesmos: o fator religioso, institucional, urbano, político e etc. Projetamos em expor toda a carga vivenciada "fluminense", em conjunto com toda a observação e implicação já efetivada em torno de toda existência concreta ou sensível, expor a peculiaridade e formas que se dão na esfera político-eleitoral deste território. Um dos maiores objetivos deste artigo, é uma ação necessária, a partir das análises eleitorais, é discutir o fator da ação do voto em um viés comportamental. Porém, fugindo dos clichês socioeconômicos e indo a partir dos fluxos regionais que nela se condiciona. Desconstruir os discursos rotineiros de sempre como: "O pobre vota mal!"; "Esse lugar é no fim do mundo! "; "Esse lugar não tem nada! ". Invés disto, construir a ideia da inquietação e questionamento, se perguntando os "por quês" de toda e qualquer constituição social. Possuindo a implicação sobre a questão dos desenvolvimentos geográficos desiguais (HARVEY, 2017), tendo o exemplo de: Por que o dito "pobre" vota mal? Por que aquela região não possui tais condições de cidadania? Por que a região não tem "nada" na infraestrutura de seu lazer?

13 Em uma contextualização de toda abordagem teórica com o artigo, podemos explicitar tais fatores que determinam uma certa "escala" particular da espacialidade descrita. As tramas territoriais não se comportam dentro de uma lógica automática de uma "concentração" de poder. Mas, sim em um ciclo de "instituições" que determinam a lógica do vivido. São instituições que cercam e demarcam um "ciclo", que se dá como ações territoriais, seja por via da Igreja Pentecostal que possui seu próprio logo, bandeira, uniforme e demarcação territorial. Agindo intensivamente como um "Estado Nação". ${ }^{3}$ Também por grupos paramilitares, como por exemplo as milícias, que como toda faç̧ão criminosa, atua com seus limites territoriais. Com toda sua "guerra" com o tráfico local pelo controle e apropriação dos territórios, seu modo de ação, e também aplica toda sua capacidade de intimidação e controle perante a vida cotidiana. A relação entre território e poder neste artigo se expressa por via de um panorama da consequência. Podemos tornar mais clara tal situação, quando o poder legitima uma ação territorial, logo, delimitando tamanha ação para uma determinada lógica de tramas (SOUZA, 1995). Seguindo tamanha lógica, qual é o impacto de toda essa carga nos modelos institucionais, como o momento eleitoral? O que se possibilita como "influência", a ocorrência de modelos de instituições que se mostram como "detentoras" dessa territorialidade sobre o eleitorado? Além de tudo, qual a relação entre esse comportamento eleitoral, os indicadores do mesmo e o concebido a esse eleitor, tendo em vista, toda uma junção da problemática na constituição "eleitoral”

\section{As dinâmicas territoriais-eleitorais}

14 Como um dos fatores chaves deste artigo, procuramos explorar de uma "certa" lógica política-eleitoral existente no território. Lógica essa que influencia determinadas tramas eleitorais que dirigem a condição territorial. Dentro desta perspectiva, será feito uma etapa de um breve estudo de trajetórias de famílias que permeiam o emaranhado político da região. Além da explanação e contextualização de nomes, que personificam em conjunto com tais famílias dinâmicas eleitorais do local. Nesta etapa bastante sensível do trabalho, procuramos trazer articulações de informações que estão postas para o público geral em portais de notícias e biografias. É importante reiterar todo um resgate para trazer todo um conhecimento empírico e teórico (não acadêmico) de difícil acesso, por um tamanho "mistério" da historicidade da região. ${ }^{5}$ 
15 Procuraremos discutir sobre pilares de famílias que regem a região, ao tocante eleitoral. Esse pilar, há protagonistas e adjacentes que alongam tamanha lógica política para a Zona Eleitoral descrita no artigo. Em seu topo, destacaremos a "Família Novaes", que se originam naturalmente do município de Nova Iguaçu/Engenheiro Paulo de Frontin. Na década de 1960, acabam se mudando para o Km 32, em Nova Iguaçu, para iniciar um negócio, narrado pelos mesmos como um empreendimento "sólido" para a região. Após esse período da família ter consolidado seu negócio, segundo os mesmos, Luiz Henrique Novaes (filho de Luiz Novaes) entra para a política por uma vontade de "combater a negligência" do governo perante a região discutida no trabalho. Luiz Henrique foi eleito vereador em 1988, tendo assumido a presidência da Câmara de Vereadores em 1989. No mesmo ano, Luiz Henrique foi brutalmente assassinado, o paradeiro e motivo da ação ainda são desconhecidas até os dias atuais. A partir deste acontecimento, o pai de Henrique, Luiz Novaes e o irmão Alexandre Novaes, mantém uma continuidade no ramo político. Segundo os mesmos, em uma espécie de "honrar" o legado do falecido irmão/filho, dando continuidade a essa "representatividade". ${ }^{6}$

16 Interessante que haja uma perspectiva sobre as trajetórias para se discutir aqui, pois é preciso desvendar qual o propósito da política na região. Para obtermos uma maior clareza, é preciso compreender a necessidade de uma espécie de "representação" da Baixada para o meio político. Essa relação de "abandono constitucional" seria dada apenas como uma representação de uma espécie de "terra sem dono"? Tais dinâmicas territoriais são de certa forma difícil defini-las, porém, é possível observar por meio da realização de um certo "poder" constituído territorialmente, podendo chegar até a observação da instrumentalização do mesmo. É possível constatar essa "formação" de poder por intermédio da realização de uma "apropriação" do território. o poder se instrumentaliza aqui, pela articulação da relação entre capital, território e legitimidade formal. O político ao praticar tal dominação de tais locais é considerado majoritariamente uma referência, ou seja, se instituí uma centralidade, sendo visto fisicamente frequentemente ou não. Para exemplificar tal teoria, seguiremos trilhando o caminho da "Família Novaes".

17 Nesta contextualização sobre a prerrogativa da "terra de ninguém", e a constituição de um "dono" para essa "terra de ninguém", buscaremos partir de uma breve investigação do ex-vereador Luiz Novaes, podendo assim obter alguns dados que possam nos trazer uma reflexão sobre tal tese. Esses dados foram obtidos a partir da Declaração de Bens ao Tribunal Regional Eleitoral do Rio de Janeiro nas Eleições Gerais de 2019, onde concorreu para o cargo de Deputado Estadual pelo Partido Socialista Brasileiro (PSB). Onde procuramos expor sobre uma

produção do controle de uma centralidade do bairro vigente de seu poder por via de uma foto de satélite da praça do Km 32 (Figura 2) e uma lista com os móveis ilustrados anteriormente 
Figura 2 - Foto de satélite da Praça do Km 32/Nova Iguaçu.

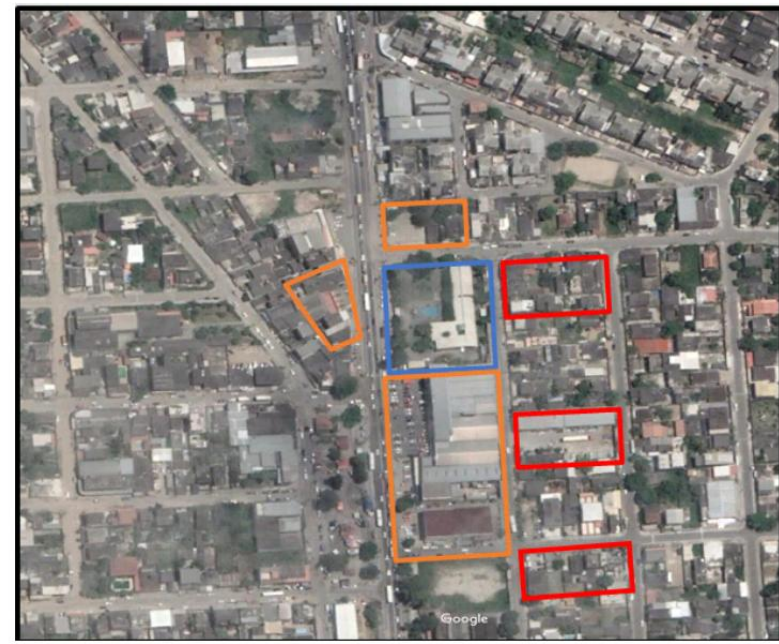

\section{Legenda}

Comércio e derivados

Loteamento de imóveis

Mansão da família Novaes

19

REPRODUÇÃO: GOOgLE EARTH

Tal fator dá margem para uma discussão sobre uma formulação de poder por via da "dominação" territorial. Tendo em vista, pelo âmbito do capital, do controle dos espaços e das espacialidades. 0 aspecto da referência se torna uma lógica ao que se diz a modulação de poderes na região, assim como uma delimitação da mesma. A rotatória entre território e poder se encontram neste aspecto, quando buscamos delimitar o seu início, final e local de encontro, podemos descobrir que a legitimação se entra em conjunto, formando "ações territoriais". Para uma maior facilidade de visualização da tese apresentada anteriormente, formulamos um quadro em formato de tabela para ilustrarmos melhor acerca da questão da dominação territorial por via de imóveis que beiram a centralidade de um bairro (Quadro 1).

Quadro 1 - Imóveis declarados por Luiz Novaes em 2018.

\begin{tabular}{|l|c|}
\hline Imóveis & Valor do imóvel \\
\hline Lotes 23 E 24 - QD 14 da BR-465, Km 32/Nova Iguaçu & $\mathrm{R} \$ 8.327,68$ \\
\hline Casa na R São Benedito, 31 - QD.02, Km 32/Nova Iguaçu & $\mathrm{R} \$ 40.000,00$ \\
\hline 11 Loteamentos na BR-465, QD.01, Km 32/Nova Iguaçu & $\mathrm{R} \$ 75.802,21$ \\
\hline Lotes 23 - 19 -20 - 21, QD.14, Km 32/Nova Iguaçu & $\mathrm{R} \$ 16.655,35$ \\
\hline $\begin{array}{l}\text { Terreno na R. São Benedito, Lote 16, QD.14, Km 32/Nova } \\
\text { Iguaçu }\end{array}$ & $\mathrm{R} \$ 40.000,00$ \\
$\begin{array}{c}\text { Lotes de terreno } n^{\circ}: 07-08-13 \text { da QD.01 na BR-465, Km } \\
\text { 32/Nova Iguaçu } \\
\text { Lote 30, QD.22 da BR-465, Km 32/Nova Iguaçu }\end{array}$ & $\mathrm{R} \$ 12.491,51$ \\
\hline
\end{tabular}

Divulgação: Divulgacand, 2019

Para uma maior exemplificação de o que seria e como se dá esse fenômeno, buscamos formular o conceito de referencial institucional, que se modula a partir da (a) - 
"aplicação do capital", em depoimento de Luiz Novaes em sua breve bibliografia familiar, o mesmo, aponta para um possível investimento da família no bairro. Trazendo uma mudança familiar, seja pelo contexto da habitação, mas, principalmente no aspecto de "negócios". Pela ausência de documentação acerca da região e principalmente pelo tema, somente nos foi possível obter tamanho panorama por depoimentos de moradores que vivem há cerca de 30 até 40 anos no bairro. Por opções dos próprios não foi possível trazer seus nomes, por ser comentários sobre uma figura pública e principalmente "política". A princípio nos foi mostrado estranhamento pela via de abordagem do pesquisador, porém, ao saber que éramos no mesmo bairro, apesar do contraste, nos foi mostrado uma melhor recepção. Foi possível observar pelos depoimentos, como essa aplicação de capital muda a configuração espacial do espaço que continha o maior fluxo, a praça do bairro (Km 32). Como a instauração de mercados como: $\mathrm{O}$ antigo Mercado Balaio e a loja de Colchões Denver, isto nos meados dos anos 80. Depoimentos esses que não demostram exatidão factuais em suas opiniões, somente deixam a perceber a representação do poder. Exemplificado aqui como referência, ouvimos palavras de referencial a tal família, como: "Manda chuva"; "Dono de tudo". Na seguinte etapa, temos, (b) - "dominação do território", tamanha ação entranha pelas diferentes ramificações e põe em execução seu poder. Se demonstra tanto fisicamente quanto simbolicamente, ultrapassa escalas da sensível ao concreto, e se concretiza como passado, presente e talvez um futuro. Em processo de continuidade, enfatizamos, em detrimento do depoimento explicitado, a termologia (c) - "Dono de Tudo", tal classificação se deve ao controle por conta da etapa anterior de dominação do território. Quando se controla os espaços de maiores circulações do bairro, como os espaços do comércio principalmente, traz uma formação de uma ideia de possessão daquela "terra". Até que a possessão vira "pertencimento", a naturalização da possessão se dá pelo detrimento da posse e o simbolismo destas estruturas. A questão das toponímias, onde o político põe seu nome ou de sua família em todo estabelecimento, hospital, etc. Para uma melhor efetivação dessa lógica, o acesso ao meio político é essencial. Pois, para legitimar o discurso institucionalmente, se é preciso utilizar a lógica do Estado, como uma grande máquina expressiva do poder.

22 Entramos na (d) - Elevação ao meio político, em um processo avançado, o detentor das terras, capital, agora detém o poder constituído, se transformando em referência. A mesma se demostra como uma saída única, o meio político se efetiva com uma contradição enorme na região. Surge como o formador dos problemas, porém, também se demostra como solução das problemáticas. Além de tudo, se adapta e converge seu poder a outras diferentes formas de poderes que, atuam ao mesmo tempo que a referência. Nos embasamos novamente em SOUZA (1995), para adaptar o conceito de (e) - Legitimação Territorial. Para demostrar os limites que se encontra tamanha referência e qual a sua extensão aos diferentes meios, seja ao concreto e sensível. Isso se exemplifica quando podemos observar alguma composição criminosa, que "comanda" um bairro, em contraposição, existe um certo político que também se dá como uma referência territorial daquele mesmo bairro. Como tamanhos poderes tão fortes no quesito simbólico e territorial podem conviver, sendo que, teoricamente esses dois grupos não pertencem a uma mesma lógica "maquinaria"?7 Não há como mensurar até onde se estende essa "cumplicidade" de poderes; entretanto, é mensurável que ambos seguem uma lógica (não exata), onde trazer a manutenção, e manter tal território em suas posses é primordial, por diferentes formas. Concluindo esta tentativa de modulação de uma "lógica", chegamos a instauração de um nível "máximo" da 
mesma. Que é o (f) - "Referencial Institucional", neste estágio, por via das explicitações anteriores, o político se torna e exerce o que consolidamos de "instituição". A personificação se dá pela referência, eventualmente qualquer trama "percorre" as suas mãos, seja pela obra, inauguração, demolição e fechamento de alguma estrutura. Pois, o mesmo se legitima com a posse de "tudo", pelo comércio, espaços habitacionais, obras de teor institucional, etc. A partir de tamanho controle das formas, o referencial dá partida para um proposito maior, onde o mesmo se encontra como a "chave". 0 teor institucional, em uma visão ontológica, para grande parte dos moradores não se parte pelo Estado e as suas estruturas (abrimos um adendo para a estrutura da polícia). Porém, se expressa pelo político, seja para abdicar de uma demanda ou para expressar alguma insatisfação. ${ }^{8}$ Para um maior entendimento desta lógica, disponibilizamos uma grade de sucessões, que prioriza determinar uma sucessão de fatores que condicionam a formação do status de referência institucional. (Quadro 2)

Táticas e estratégias do emaranhado político local: acesso à cidadania como uma ferramenta política

Nesta etapa do artigo, devemos partir de duas premissas, que é a relação da consolidação de uma constituição como forma e a prática desta formulação de poder. No campo das ações diretas e práticas, entramos na introdução das ferramentas e instrumentalizações dos nossos personagens em uma viabilização de sua efetivação como o ser referencial. Como foi elucidado na etapa anterior, a construção e formação de tais personagens como esse ser referencial, se dá pela posse de diversas espécies de poderes em suas diversas práticas. Neste estágio, avançamos para o campo efetivo, como se portam como referências e como gerenciam tal forma de poder. Por uma ausência de abundância de fontes sobre as práticas políticas na região, esta etapa do artigo se viabiliza por fontes oriundas de mídias de pequeno porte, além de uma importante implicação empírica do pesquisador, expondo toda sua vivência e reflexão fluminense.

Quadro 2 - A lógica do "Referencial Institucional”.

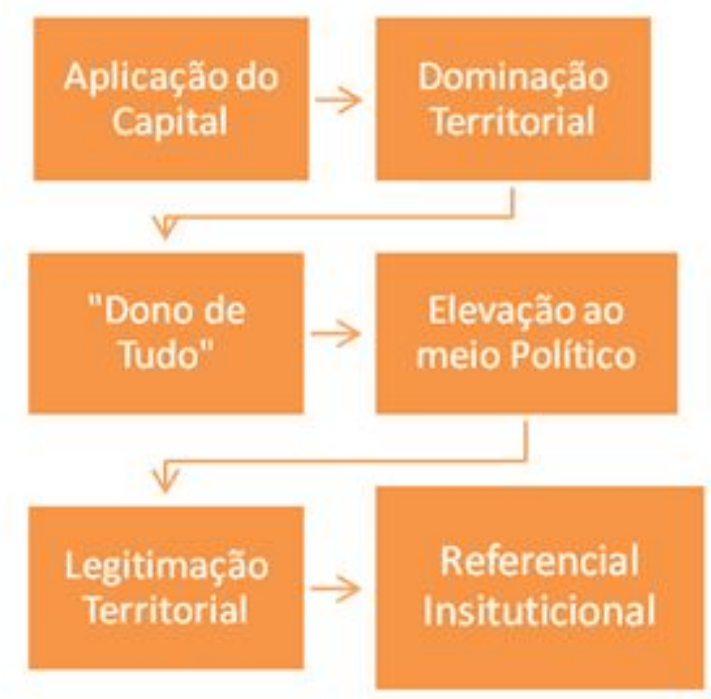

Organização: 0 autor.

Espaço e Economia, 16 | 2019 
24 Para um melhor entendimento do assunto, reiteramos a importância do resgate de uma historicidade do território. Como citado anteriormente, a espacialidade discutida no artigo se condiciona como algo além das funcionalidades estruturais. O que justifica e forma diferentes modelos de poderes, é a formação de uma própria face, que foi caracterizado neste artigo por "dinâmicas territoriais". Após tamanho resgate: Como podemos caracterizar as formas discutidas? O que se caracteriza como: Estado, cidadania, direito e a própria institucionalidade?

25 Para chegarmos ao ponto de encontro das duas premissas inicialmente explicitadas no início desta etapa, devemos contextualizar as instrumentalizações com uma espécie de "herança" da política clientelista no Rio de Janeiro. A partir desta perspectiva, podemos exemplificar tal herança não por uma espécie de "compra de voto", claramente tal prática pode vir a ocorrer, mas não é o ponto principal. Onde queremos chegar nessa discussão é a realização de uma construção de uma imagem. Nesta imagem, está o político, individuo, porém, o mesmo está acompanhado com o referencial político. Em conjunto com tal referencial, se cria a partir daí uma espécie de constituição, a máquina se condiciona em uma imagem. O Estado, instituição e formas se unifica em uma imagem e se condiciona como político. A questão se põe em uma via ontológica, o eleitor, por toda uma carga negligenciada por conta de uma centralidade política já explicitada, olha ao seu redor e só enxerga o político "local" como uma chave de acesso às instituições formais. Neste contexto, poderemos observar: compras de votos por cargos públicos, agendamento e adiantamento de atendimentos de um teor grave em hospitais públicos por indicação do político, cumprimento e demanda de certas obras públicas, etc.

26 Por este motivo há de se desconstruir as representações banais sobre "o pobre votar mal" ou "pobre está mais suscetível a ser manipulado". O eleitor está posto consciente de sua realidade concreta a todo instante, há fatores que podem trazer indicadores eleitorais distintos, como formação, idade, religião e condição social. Entretanto, a construção de um fenômeno quase "mágico" de manipulação político-eleitora não passa de uma análise limitada sobre os comportamentos eleitoreiros. 0 mito da manipulação ao extremo no aspecto eleitoral se esvai quando pensamos nas condições que se está posto tais eleitorados. É na peculiaridade e no cuidado ao observar que podemos identificar diferentes formas de poder, mesmo que o modelo em uma escala maior (Estado-Nação), seja instituído federalmente. Na perspectiva das especificidades, podemos elucidar que o eleitor, a partir de sua consciência concreta, se realiza pela "exceção" como a realidade concreta posta. Podemos exemplificar essa tese por via de uma obra por exemplo, uma simples construção que se determina como algo "básico" no meio político ao se referir a "cidadania". Entretanto, tal realização se torna uma transformação máxima, por uma negligência histórica do local, o eleitor se vê "privilegiado", "orgulhoso" e acima de tudo "representado". O eleitor, ao ver ao seu redor, se dá conta que somente sobra aquilo que foi lhe instituído, o mesmo será apoiador ferrenho daquele que fez "algo". O objeto oculto pode ser qualquer ação ou “atenção" governamental em qualquer intensidade, o representante do executivo que o fizer, será considerado pela parte da população.

27 Após toda a problemática apresentada, a instrumentalização política se torna prática efetiva por via do acesso a cidadania. Podemos averiguar isso pelo intermédio entre uma dificuldade de acesso ao meio físico ${ }^{9}$ e uma ausência de uma orientação ao cidadão para ter acesso aos seus documentos, previdência, etc. $\mathrm{O}$ acesso a cidadania é uma tese 
bastante pertinente na região, seja individualmente, indo até ao coletivo, como: pavimentações de ruas, esgoto tratado, água tratada, etc. Neste tabu imenso, alguns políticos locais tendem a se "comprometerem" a resolver esses problemas, que atravessam décadas. Porém, utilizam de certas maneiras simbólicas de trazer a representação da institucionalidade para si próprio. Tais maneiras atravessaram até o pesquisador, que em sua vida sempre pode observar no bairro a execução de tal prática.

Entretanto, esse aspecto instrumentalizado não se restringe somente aos políticos da escala local, criaremos um adendo a uma ação política de escala estadual. Em 2014, no auge do período eleitoral das Eleições Gerais, o até então candidato a reeleição ao cargo de Governador do Estado do Rio de Janeiro, Luiz Fernando "Pezão" e o Prefeito de Nova Iguaçu Nelson Bornier, por via do programa do Governo do Estado. Prontificaram o

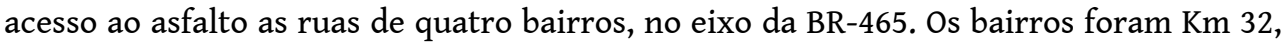
Prados Verdes, Lagoinha e Jardim Guandu. Lembrando que, o acesso a demandas básicas da vida na região historicamente é escasso, mesmo após muita demanda pelo asfalto, as mesmas nunca foram asfaltadas. Tamanho foi o alvoroço, que muitos se perguntaram quem foi o político que providenciou "tamanha ação" na região. Os governantes em questão, fizeram diversos comícios na região em questão, tendo como objetivo uma apropriação da obra, como citado anteriormente, se alguém disser que fez o "mínimo" será considerado pelo corpo eleitoral. No mesmo contexto, os políticos em questão se apresentam como pessoas que conhecem uma realidade local, conhecendo os problemas e se põem como a solução dos mesmos. Tendo claramente noção que tais faixas e dizeres estavam expostas nas centralidades de cada bairro, em suas praças. Tamanha "satisfação" pode ser evidenciada pelo Jornal Folha do Iguassúi ${ }^{10}$, portal de notícias de pequena mídia local que trouxe relatos sobre tamanhas obras:

Morando no bairro São Francisco (Km 32) há mais de 50 anos, o aposentado Moacir Ramos, 66, disse que não acreditava em ver a sua rua (São Marcos) ser asfaltada. "Muitos vizinhos já morreram e não viram as melhorias aqui. Graças a Deus não vou mais pisar em lama", resumiu. "Pezão e Bornier prometeram e cumpriram. Muitos políticos passaram por aqui e só enganaram os moradores. "Época de chuva era lama pura, esse tempo agora ficou para trás”, completou Célio César, 50, que mora na Rua São Marcos. (CAMARA, 2014)

Aproveitando o contexto de "identificação" da região, é possível exemplificar este argumento na fala novamente do Ex-Governador Luiz Fernando Pezão:

Pezão diz: "Enfim, não estou aqui de "caô" e nem para contar história. Estudei na Universidade Rural em 1979. Passava aqui e via esta região abandonada. E continuou assim por muitos anos. Agora vamos sanear, drenar e pavimentar para darmos qualidade de vida aos moradores", disse Pezão, muito aplaudido, ao lado de Bornier. (CAMARA, 2014)

Ao trazer novamente o personagem político do até então prefeito de Nova Iguaçu, Nelson Bornier (2012-2016), evidenciamos nas Eleições para a prefeitura de Nova Iguaçu em 2016. Onde, faltando cerca de um mês para as eleições, é inaugurado a Clínica da Família do Km $32 .{ }^{11}$ Obra essa que já estava em curso, há cerca de três anos, e desde 2014 permaneceu estagnada sem nenhuma atualização, como relata a última fiscalização de Bornier antes da inauguração. ${ }^{12}$ Entretanto, a obra é "incrivelmente" acelerada e terminada a tempo das eleições, trazendo uma espécie de "glória" ao prefeito. Infelizmente para o ex-prefeito, a obra não refletiu nos resultados finais de seu almejado cargo. Porém, ainda se expressa como uma prática eleitoral, ação semelhante aos casos da gestão estadual de governos do PSDB em São Paulo. ${ }^{13}$ 


\section{Considerações finais}

31 Após toda discussão, é possível perceber que essa análise dessa Geografia Eleitoral foi proposta em dissertar e expor sobre a instrumentalização política da região em consequência de sua construção histórica. A mesma se executa pela consequência da ausência. Por conta dessa ausência, entramos em ciclos políticos que ocasionam uma alienação da estrutura política regional. Tal ciclo dá por consequência modelos de ações que tendem a constituir um completo domínio território de uma ramificação, que em nosso caso damos enfoque a uma família.

32 Como citado, a utilização da cidadania como uma ferramenta política de bairro, promessas de obras de infraestrutura básica como saneamento, efetivação de serviços de coleta e principalmente pelo fator estrutural da educação. Além de ser perceptível uma espécie de controle territorial e restruturação espacial por via do controle dos imóveis que rodeiam a centralidade de fluxos do bairro, que tivemos como exemplo, o bairro do Km 32. Seja na inauguração de infraestrutura componente da sociedade, por exemplo: Agências bancárias, mercados, etc. Citamos as espacialidades por via da não restrição, indo da constituição da materialidade da imaterialidade do território. Já os espaços podem ser viabilizados, em detrimento da construção concreta da região, onde é acompanhada pela família citada no artigo. Nesse fator de constituição de uma formulação de poder, que se condiciona como o controle das centralidades de um bairro. Podemos perceber que essa formulação ultrapassa categorias que pertencem a uma lógica subalterna ao Estado. Alegamos isto tendo base exemplos como: Construção de um estacionamento de um centro comercial que toma parte de uma via que pertence a um nivelamento federal. Por deter esse status de referencial institucional, o mesmo ultrapassa a lógica que é disseminada de "se votar certo, tal parâmetro muda". Pois, se pensarmos que, por exemplo, a família Novaes está instalada no local, há cerca de cinco décadas e até o atual momento mantém seu poder sem ao menos estar presente como parlamentar na Câmara Municipal de Nova Iguaçu, tal argumento cai por vez pela obviedade da situação contextualizada neste artigo.

33 Em um tom de finalização, há de ser reiterado o aguçamento em nosso olhar de observação acerca das tramas das menores escalas, sendo mais incisiva na categoria Bairro. Visto que as práticas citadas neste trabalho por parte de um corpo formal político regional não se condicionam somente na escala local, tendo como exemplo os vereadores, prefeitos e governadores. Contrariando assim uma representação criada por uma herança de um "coronelismo primitivo" das regiões dos sertões outrora diversos discursos que se propagam nas representações midiáticas que se dão em locais "isolados". Quando enxergamos tais ações, o discurso comum que é propagado é que tais práticas políticas que não se remetem a "complexidade" da metrópole. Porém, na centralidade e grandiosidade que signifique o Governo do Estado do Rio de Janeiro, o mesmo também se insere nas mais diversas escalas nesta lógica como um modelo político operante. Ou seja, tamanha prática que herda uma política de cunho "clientelista" não se condiciona somente na escala do "atraso" da Baixada Fluminense, contradizendo os discursos predominantes acerca da região. Finalizamos tamanha exposição com uma indagação: esse modelo operante está entranhado na política do Rio de Janeiro exclusivamente em seus mais diversos paradigmas políticos ou pertence como uma herança da formação política brasileira? 


\section{BIBLIOGRAFIA}

ALVES, José Claudio. Dos barões ao Extermínio: uma história de violência na Baixada Fluminense. Duque de Caxias: APPH CLIO, 2003.

BAITZ, Ricardo. Implicação: um novo sedimento a se explorar na Geografia? In: Boletim Paulista de Geografia, nº 84, jul. 2016.

BARRETO, Alessandra Siqueira. Notícias de uma Guerra: estratégias, ameaças e orações. Horizontes Antropológicos. Porto Alegre. Ano 13, n.27, p.183-212, jan-jun. 2007.

HAESBAERT, Rogério. Dos múltiplos territórios á multiterritorialidade. Porto Alegre, 2004.

OZÓRIO, Elaine Cristina. O Processo de Reprodução do Espaço Urbano Na Cidade de Nova Iguaçu RJ (1900 - 2007). Dissertação apresentada ao Curso de Mestrado do Programa de Pós-Graduação em Planejamento Urbano e Regional da Universidade Federal do Rio de Janeiro - UFRJ. Rio de Janeiro, 2007

RAFFESTIN, Claude. Por uma geografia do poder. São Paulo: Ática, 1993.

ROCHA, André Santos daROCHA, André Santos da. "As representações ideais de um território": dinâmica econômica e política, agentes e a produção de sentidos na apropriação territorial da Baixada Fluminense". Tese (Doutorado em Geografia) - Universidade Federal do Rio de Janeiro, Instituto de Geociências, PPGG, Rio de Janeiro, 2014. Geografia Política das Representações - Projetos e Jogos de Poder na Apropriação da Baixada Fluminense. 2015. Rio de Janeiro.

SANGUIN, A. L. Geografia Política. Barcelona: Ed. Oikos-Tau, 1981.

SANTOS, Milton. O Espaço do Cidadão. São Paulo: EDUSP, 1987.

SILVA, Nathan Ferreira da. A ação dos agentes sociais na produção do espaço urbano. I Congresso de Geografia e Atualidades - UNESP. São Paulo, 2015.

SIMÕES, Manoel Ricardo. A cidade Estilhaçada - reestruturação econômica e emancipações municipais na Baixada Fluminense. Programa de Pós-Graduação em Geografia UFF. (Tese de doutorado), 2006.

SOUZA, Marcelo Lopes de. Território e (des)territorialização. In: M. L. Souza, Os conceitos fundamentais da pesquisa sócio-espacial. Rio de Janeiro: Bertrand Brasil, 2013.

TRINDADE, Adriana de Alburqueque. O estilo político da Bica D'Água: O chaguismo da Guanabara 1969-1974. Biblioteca Digital da Função Getulio Vargas - CPDOC-FGV. Rio de Janeiro, 2000. Disponível em <: http://bibliotecadigital.fgv.br/dspace/bitstream/handle/ 10438/6580/801.pdf.txt?sequence=2:> Acesso em dez, 2018.

\section{NOTAS}

1. Constituições essas nos referimos a sua formação a uma intensa urbanização, a partir dos anos 70, obtendo sua "face" urbana. Recomendo ver também, OZÓRIO, 2007, O processo de (re)produção do espaço urbano na cidade de Nova Iguaçu-RJ: (1990-2007) e também SILVA, Nathan Ferreira da. A ação dos agentes sociais na produção do espaço urbano. São Paulo, 2015. 
2. “A periferia metropolitana estaria sendo modificada para abrigar uma classe média oriunda da própria população periférica que alcançou maiores rendimentos e/ou mobilidade residencial da cidade do Rio de Janeiro em direção à Nova Iguaçu, por motivos diversos. " (SILVA, 2015).

3. Atribuímos tamanho exemplo, por conta da prática de Igrejas na região, que possuem um caráter "territorial", que abordam principalmente práticas de identidade. Onde, por vida de tais práticas, as mesmas confeccionaram o logotipo "Jesus", com uma fonte própria, em um produto de design. A partir de tal fonte, foi-se criado uma variação de figuras "identitárias", como: pinturas, bandeiras, faixas e principalmente placas.

4. Tal constituição pode ser definida por conta de uma produção e reprodução de diferentes tramas. Como a própria absorção de valores familiares, as conversas particulares com as pessoas ao redor, campanhas eleitorais e com o fenômeno atual da atuação da internet na difusão de informações (sendo verdadeiras ou não). A eleição é um fenômeno que junta oposições de escalas, é o momento onde se junta as constituições individuais do vivido, em uma ação que se molda como um "coletivo", que é o voto por si só.

5. Esse mistério traz uma maior dificuldade ao resgate de informações em portais para a pesquisa, a maioria dos materiais que se planificam neste artigo, foram constatados dentro de um modo empírico, constatados por trabalhos de campo e entrevistas ou reproduzido por mídias de pequeno porte.

6. Toda informação contida neste parágrafo está disponível na informação da página oficial do Facebook de Luiz Novaes, fonte: https://www.facebook.com/LuizNovaesOficial/. - Acesso em fev 2019.

7. Há quem teorize e apresenta a questão das composições criminosas em relações com o meio institucional, principalmente com o emaranhado político. Acreditamos em tal teoria, porém para uma exemplificação honesta e clara, é preciso ter aspectos factuais em mãos para a inserção de tal ideia. Em fins de honestidade, afastamos tamanha questão grave do artigo, pela falta de arquivos factuais.

8. Em uma contextualização maior, partimos da premissa da negligencia institucional como uma naturalidade na região. A instituição como parte de "Estado", se evidencia pelos grupos criminosos que comandam o local (tal como justiça ou até serviço de "policiamento") e pelos políticos como a prática clientelista (acesso a hospitais, cidadanias em geral).

9. Ao nos referirmos a uma dificuldade físico, temos que ter em mente, a questão dos deslocamentos, o percurso para o Centro de Nova Iguaçu para a emissão de qualquer documento leva cerca de 2 horas, por via do transporte público que custa $(\mathrm{R} \$ 4,40)$. Além de pelas diferentes mudanças e evolução urbana de Nova Iguaçu, a RJ -105 (Estrada de Madureira) se encontra sobrecarregada, por conta da massiva carga de automóveis. Também sendo um percurso longo e cansativo (cerca de $22 \mathrm{~km}$ ).

10. O jornal foca em trazer as tramas cotidianas que Nova Iguaçu traz, da política (principalmente) até o esporte. Atua, teoricamente como uma mídia independente, redigido por Wademberg Camara. Fonte da notícia citada no artigo: http:// jornalfolhadoiguassu.blogspot.com/2014/04/pezao-e-bornier-inauguram-obras-no-km.html Acesso em jan 2019.

11. De acordo com a própria Secretaria de Saúde de Nova Iguaçu, a Clínica da Família do Km 32 foi inaugurada no dia 23 de setembro as 16 horas. Faltando cerca de um mês para o período eleitoral, que foi realizado no dia 30 de outubro de 2016.

12. Esta última visita foi realizada no dia 30 de junho de 2016, a obra tinha previsão para inauguração para agosto de 2015. A fonte pode ser obtida pelo próprio portal oficial da prefeitura de Nova Iguaçu: http://www.novaiguacu.rj.gov.br/2014/06/30/bornier-vistoria-obras-daunidade-24-horas-arquiteta-patricia-marinho/ - Acesso em jan 2019. 
13. Afirmamos isso em base levantamento organizado pela Folha de São Paulo. Fonte: https:// www1.folha.uol.com.br/cotidiano/2018/04/alckmin-entrega-em-74-dias-de-ano-eleitoral-maismetro-que-em-6-anos.shtml - Acesso em jan 2019.

\section{RESUMOS}

No presente artigo, apresentamos as seguintes relações: o emaranhado eleitoral com a composição da estrutura do território, e a constituição de uma "estrutura" que pode ser observada pelo exercício e demonstração das variáveis formas de poder. A junção desses dois conceitos é primordial para este trabalho; por intermédio deles, trazemos uma elucidação de uma forma constituída a partir da própria historicidade da região. E a partir da mesma, é possível construir uma própria conjuntura político-eleitoral que, consequentemente, acompanha as tramas da política em suas diversas escalas. O território se apresenta como uma categoria conceitual central, condicionando-se e moldando-se a partir de representações. Neste artigo, nos remetemos à $84^{\circ}$ Zona Eleitoral do Estado do Rio de Janeiro, que abrange parte do município de Nova Iguaçu. Por via de uma implicação territorial, o autor procura explicitar uma lógica contínua no meio eleitoreiro, demostrado por via de famílias que estão inseridas no ramo eleitoral efetivamente desde o período de reinstaurarão da República brasileira em 1988, por via da efetivação da Constituição Brasileira. Dentre uma das teses mais efervescente deste artigo, procuramos estabelecer a condição de dominação territorial como uma perpetuação da condição político-social, por via da estrutura criada pelo referencial institucional. Tendo em pauta a condição de referencial sendo modelada pelas negligências territoriais, procuramos expor tal problemática por via da Geografia Eleitoral, uma ramificação do campo da Geografia Política. Além de, pela mesma, procurar demostrar o efeito em práticas desta lógica a partir da influência, seja por ações dinâmicas de poderes, influências eleitorais, táticas de manutenção de poderes do território e práticas eleitorais, tendo como enfoque a obtenção da cidadania como ferramenta política.

In the present article, we show the following relations: the electoral tangle with the composition of the territory structure, and the constitution of a "structure" that can be observed by the exercise and demonstration of the variable forms of power. The junctions of these two concepts are primordial for this work; through them, we bring an elucidation of a form constituted from the very historicity of the region. And from this, it is possible to construct a political-electoral conjuncture that, consequently, accompanies the plots of politics at its various scales. The territory presents itself as a central conceptual category, conditioning and shaping itself from representations. In this article, we refer to the 84th Electoral Zone of the State of Rio de Janeiro, which covers part of the municipality of Nova Iguaçu. By means of a territorial implication, the author tries to explain a continuous logic in the electoral environment, demonstrated by means of families that have been inserted in the electoral means since the period of reinstatement of the Brazilian Republic in 1988, by the effectiveness of the Brazilian Constitution. Among one of the most effervescent theses of this article, we try to establish the condition of territorial domination as a perpetuation of the political-social condition, through the structure created by the institutional reference. Taking into account the condition of reference being shaped by territorial negligence. We try to expose this problem through Electoral Geography, a branch of the field of Political Geography. Besides, pretend to demonstrate the effect in practices of this 
logic from the influence, be it by dynamic actions of powers, electoral influences, tactics of maintaining territorial powers, and the electoral practices as ours focus, having the example of the seeking of citizen rights or citizenship as a political tool.

Dans cet article, les relations suivantes sont présentées: la conjoncture électoral avec la composition de la structure territoriale, et la constitution d'une "structure" qui peut être observée par l'exercice et la démonstration des formes variables du pouvoir. La combinaison de ces deux concepts sont primordiales pour cette étude; basé sur eux, nous apportons um récit d'une forme constituée de l'historicité de la région. Et à partir de là, il est possible de construire une conjoncture politique-électorale qui accompagne par conséquent les réseaux politique à diverses échelles. Le territoire se présente comme un concept central, conditionnant et se façonnant à partir de représentations. Nous allons faire référence à la 84ème Zone Électorale de l'État de Rio de Janeiro, qui couvre la municipalité de Nova Iguaçu. Avec une approche territoriale, l'auteur cherche à expliquer une logique de continuité dans le domaine électoral, illustrée par des familles insérées dans les moyens électoraux depuis la période de réintégration de la République brésilienne en 1988, grâce à la consommation de la Constitution brésilienne. Parmi les thèses les plus effervescentes de cet article, nous essayons d'établir la condition de domination territoriale comme une perpétuation de la condition politique-sociale, à travers la structure créée par la cadre institutionnelle, compte tenu de la condition de référence façonnée par la négligence territoriale. Nous essayons d'exposer ce problème par la géographie électorale, une branche du domaine de la géographie politique, d'ailleurs, cherchent à démontrer l'effet de cette logique sur la base de l'influence, que ce soit par les actions dynamiques du pouvoir, les influences électorales, les tactiques de maintien des pouvoirs territoriaux et les pratiques électorales, visant l'obtention de la citoyenneté comme instrument politique.

En el presente artículo, presentamos las siguientes relaciones: el enredo electoral con la composición de la estructura del territorio, y la constitución de una "estructura" que puede observarse mediante el ejercicio y la demostración de las formas variables de poder. La combinación de estos dos conceptos es primordial para este trabajo; A través de ellos traemos una aclaración en una forma constituida por la propia historicidad de la región. Y a partir de esto, es posible construir una coyuntura político-electoral propia que, en consecuencia, acompañe las tramas de la política en sus diversas escalas. El territorio se presenta como una categoría conceptual central, condicionándose y formándose a partir de representaciones. En este artículo, nos referimos a la 84a Zona Electoral del Estado de Río de Janeiro, que cubre parte del municipio de Nova Iguaçu. A través de una implicación territorial, el autor intenta explicar una lógica continua en el entorno electoral, demostrada a través de las familias que se insertan en la rama electoral de manera efectiva desde el período de reincorporación de la República de Brasil en 1988, a través de la implementación de la Constitución brasileña. Entre una de las tesis más efervescentes de este artículo, buscamos establecer la condición de dominación territorial como una perpetuación de la condición político-social, a través de la estructura creada por el marco institucional. Teniendo en cuenta la condición referencial modelada por negligencia territorial, buscamos exponer esa problemática a través de la Geografía Electoral, una rama del campo de la Geografía Política. Además, busca demostrar el efecto sobre las prácticas de esta lógica a partir de la influencia, ya sea mediante acciones dinámicas de poderes, influencias electorales, tácticas para mantener los poderes territoriales y prácticas electorales, centrándose en la obtención de la ciudadanía como herramienta política. . 
ÍNDICE

Palavras-chave: Geografia Eleitoral, Geografia Política, Baixada Fluminense, Território.

Mots-clés: Géographie électorale, Géographie politique, Baixada Fluminense, Territoire.

Palabras claves: Geografía Electoral, Geografía Política, Baixada Fluminense, Territorio.

Keywords: Electoral Geography, Political Geography, Baixada Fluminense, Territory.

\section{AUTOR}

\section{BERNARDO BISPO SANTOS}

Graduando em Licenciatura em Geografia pela Universidade Federal Rural do Rio de Janeiro (UFRRJ). Sendo bolsista de Iniciação Científica (FAPERJ/IC 2018-2019 e 2019-2020) desenvolvendo a pesquisa "Geografia Eleitoral: as articulações e relações das tramas, redes e fluxos no território fluminense" sendo orientado pelo Dr. Márcio Rufino Silva, membro do grupo de pesquisa "Por uma 